\title{
A prospective study of colonoscopy practice in the UK today: are we adequately prepared for national colorectal cancer screening tomorrow?
}

\author{
C J A Bowles, R Leicester, C Romaya, E Swarbrick, C B Williams, O Epstein
}

Gut 2004;53:277-283. doi: 10.1136/gut.2003.016436

See end of article for authors' affiliations

........

Correspondence to: Dr O Epstein, Department of Gastroenterology, Royal Free Hospital, Pond St, London NW3 2QG, UK; o.epstein@btinternet.com

Accepted for publication 26 June 2003

\begin{abstract}
Aim: To study the availability and quality of adult and paediatric colonoscopy in three National Health Service (NHS) regions.

Method: A prospective four month study of colonoscopies in North East Thames, West Midlands, and East Anglia.

Patients: Subjects undergoing colonoscopy in 68 endoscopy units.

Results: A total of 9223 colonoscopies were studied. The mean number of colonoscopies performed over the four month period was 142 in district general hospitals and 213 in teaching hospitals. Intravenous sedation was administered in $94.6 \%$ of procedures, but $2.2 \%$ and $11.4 \%$ of "at risk" patients did not have continuous venous access or did not receive supplemental oxygen, respectively. Caecal intubation was recorded in $76.9 \%$ of procedures but the adjusted caecal intubation rate was only $56.9 \%$. Reasons for failing to reach the caecum included patient discomfort (34.7\%), looping (29.7\%), and poor bowel preparation (19.6\%). A normal colonoscopy was reported in $42.1 \%$. The most common diagnosis was polyps (22.5\%) followed by diverticular disease (14.9\%). Inflammatory bowel disease was recorded in $13.9 \%$ and carcinoma in 3.8\%. Only half of the patients remembered being told of possible adverse events prior to the procedure. Rectal bleeding requiring admission following colonoscopy was reported in six patients. The overall perforation rate was 1:769 and colonoscopy was considered a possible factor in six deaths occurring within 30 days of the procedure. Only 17.0\% of colonoscopists had received supervised training for their first 100 colonoscopies and only $39.3 \%$ had attended a training course.

Conclusion: There is serious under provision of colonoscopy service in most NHS hospitals. Endoscopy sedation guidelines are not always adhered to and there is a wide variation in practice between units. Colonoscopy is often incomplete and does not achieve the target $90 \%$ caecal intubation rate. Serious complications of colonoscopy were comparable with previous studies. Training in colonoscopy is often inadequate and improved practice should result from better training.
\end{abstract}

$\mathrm{T}$ he study of the availability and quality of colonoscopy was set up with the support of the British Society of Gastroenterology (BSG), the Royal College of Physicians of London, the Royal College of Surgeons of England, the Royal College of Radiologists, the Association of Surgeons of Great Britain and Ireland, and the Association of Coloproctology of Great Britain and Ireland.

The first successful total colonoscopy using the "fibreoptic coloscope" was reported in 1966 by Overholt and Pollard. ${ }^{1}$ By the turn of the millennium, colonoscopy had emerged as the first line imaging investigation of the colon. The procedure is more sensitive than radiological imaging and offers a range of therapeutic options. However, colonoscopy is a difficult skill to master. The procedure is often painful for the patient. Over sedation, perforation, bleeding, and procedure related death remain much feared complications.

Colorectal cancer is common, with more than 30000 people being affected each year in the UK. ${ }^{2}$ Several studies have shown that implementation of a screening programme reduces mortality from colorectal cancer in asymptomatic individuals..$^{3-5}$ Pilot studies are currently underway in the UK and whichever testing strategy is deployed in a national screening programme, large scale colonoscopy will be required to remove polyps and obtain histology. In addition, long term surveillance schedules will be necessary to prevent recurrence of benign and malignant tumours.
In the UK, there is no information on who performs colonoscopy and how they were trained. A survey conducted in 1987 indicated that only one in six of English hospitals offered an appropriate colonoscopy service. ${ }^{6}$ The completeness of colonoscopy was also highly variable, ranging from $55 \%$ to $97 \%$. In 1999, MacFarlane et al reported that only half of the endoscopy units provided an adequate colonoscopy service. ${ }^{7}$

There have been six large prospective studies of complications following diagnostic and therapeutic colonoscopy, ${ }^{8-13}$ and four retrospective studies of at least 10000 patients. ${ }^{14-17}$ These studies provide helpful benchmarks for assessing complications.

The purpose of this large multicentre prospective study was to assess the availability and quality of colonoscopy in a cross section of gastroenterology centres in the UK. The study provides a platform for recommending standards of practice and methods for achieving safe high quality colonoscopy.

\section{METHODS}

All hospitals in three representative National Health Service (NHS) regions were approached to participate in the study

Abbreviations: NHS, National Health Service; BSG, British Society of Gastroenterology; DGH, District General Hospital; ASA, American Society of Anesthesiology; JAG, Joint Advisory Group 


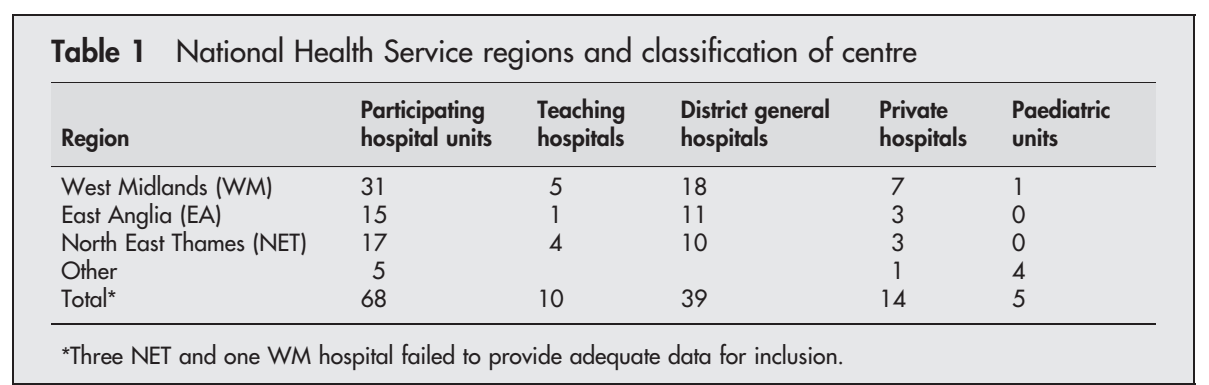

(table 1). In addition, major private health providers operating in these regions were approached to participate and several paediatric hospitals were asked to enrol (table 1). Paediatric colonoscopy is a highly specialised tertiary care activity and therefore paediatric units were invited to participate from outside the three regions chosen for the adult study.

Four detailed questionnaires were developed and printed in booklet form. The first, comprising 45 compulsory questions, recorded patient demographic details and the details of each colonoscopy. Questions were designed to record indications for the procedure, sedation practice, extent of visualisation of the colon, endoscopic diagnosis, therapeutic interventions, and both immediate and 30 day complications. The second questionnaire detailed the staffing and practices of individual units. A third questionnaire recorded the training and experience of the colonoscopists, and the fourth sampled 1200 patients and their experience of the procedure.

Each unit was asked to complete the procedure related questionnaire on all consecutive colonoscopies over a four month period. Wherever possible, a tick box format was used and the pages designed to be read by Formic (Formic Ltd), an automated optical scanning device with integrated data capture software. The research fellow (CJAB) visited the participating units to explain the aims and objectives of the project and to discuss the questionnaires and organisational details with clinicians, endoscopy staff, and audit personnel. In each hospital, a mechanism was established to report complications occurring within 30 days of the procedure.

\section{RESULTS}

Sixty eight units provided information on 9223 colonoscopies (table 1), 234 colonoscopists, and 599 patients. Four of 54 $(7.5 \%)$ NHS units in the three regions failed to provide adequate data for inclusion. Only 41 of the 68 participating units returned the endoscopy unit questionnaire. The number of colonoscopies reported from the 49 NHS adult District General Hospitals (DGHs) and teaching hospitals ranged from 55 to 346 (mean 162). Private hospitals completed returns on 9-458 colonoscopies (mean 83) and paediatric hospitals reported on 10-46 procedures (mean 24). DGHs provided information on almost two thirds of the colonoscopies. The sex ratio and functional status of patients undergoing colonoscopy are indicated in table 2 . The ages of the adult population ranged from 16 to 95 years (mean 58) and $14.1 \%$ were 75 years or older.

\section{Indications for colonoscopy}

Diagnostic procedures accounted for $61.2 \%$, therapeutic for $6.8 \%$, and surveillance for $40.3 \%$. More than one indication was recorded in $36 \%$ of patients. The most common indications for colonoscopy were investigation of rectal bleeding (19.9\%) followed by polyp follow up (16.5\%), change of bowel habit (14.6\%), diarrhoea (11.8\%), abdominal pain $(10.9 \%)$, and previous colorectal cancer $(10.7 \%)$.

\section{Bowel preparation}

A single policy on bowel preparation was used by 34/41 $(82.9 \%)$ units. In the remainder, individual colonoscopists determined their preferred regimen. Most units favoured a single agent bowel preparation. Sodium picosulphate (Picolax) was used in $36.8 \%$ of examinations, polyethylene glycol preparations (Klean Prep) in 20.7\%, and sodium phosphate (Fleet) in $15.6 \%$.

\section{Sedation practice, reversal agents, and antispasmodics}

Prior to sedation, the functional status of all patients was recorded according to the American Society of Anesthesiology (ASA) classification of physical status (table 2). Patients are classified as "at risk" if they are in ASA class 3 or above. ASA class 3 or 4 was recorded in $3.4 \%$ of patients. Continuous intravenous access was established in $93.1 \%$ of patients. In those with continuous intravenous access, a plastic cannula was used in 7470/8583 (87\%), an indwelling needle ("butterfly") in $935 / 8583(10.9 \%)$, and a central line in $62 / 8583$ $(0.7 \%)$ patients. In sedated patients, supplemental oxygen therapy was administered in 6266/8721 (71.8\%) and pulse oximeter monitoring was used in 8200/8721 (94.0\%). Continuous intravenous access was not established in 7/316 (2.2\%) ASA class 3 and 4 patients and supplemental oxygen was not administered to 36/316 (11.4\%) "at risk" patients.

Sedation was administered in $94.6 \%$ of the procedures. A range of sedative and analgesic regimens were reported. The most common combination was pethidine and midazolam (57.8\% of colonoscopies) and there was a wide range of doses. The mode dose of midazolam was $5.0 \mathrm{mg}$ (range 0.520.0 ), with $1956 / 7707(25.4 \%)$ receiving greater than $5 \mathrm{mg}$. The mode dose of diazemuls was $10 \mathrm{mg}$ (range 1.0-30.0), with 76/901 $(8.4 \%)$ receiving greater than $20 \mathrm{mg}$. The mode dose of pethidine was $50 \mathrm{mg}$ (range 10-100). In patients receiving combined sedation and analgesia, the benzodiazepine was administered prior to the opiate in $2087 / 7533$ $(27.7 \%)$ patients.

In paediatric units, $65.6 \%$ of colonoscopies were performed under general anaesthetic. In adults, colonoscopy under general anaesthesia was reported in $1.3 \%$ of private, $0.3 \%$ of DGH, and $0.2 \%$ of teaching hospital patients.

Reversal agents (for example, flumazenil and naloxone) were administered in $3.4 \%$ of procedures. Indications for reversal included "routine use", "slow to recover", "end of list", "respiratory depression", and "unresponsiveness". Hyoscine butylbromide (Buscopan) was administered in $20.6 \%$ of procedures and almost always as a $20 \mathrm{mg}$ dose.

\section{The colonoscopic examination}

\section{Caecal intubation}

A "complete colonoscopy" refers to the passage of the colonoscope to the caecum or terminal ileum. The endoscopist assessed completion of the colonoscopy by using one or more landmarks to identify the caecum. These included transillumination $(34.7 \%)$, tri-radiate fold $(70.0 \%)$, appendiceal orifice $(42.7 \%)$, ileocaecal valve $(67.9 \%)$, intubation of 
Table 2 Age, sex ratio, and functional (ASA) status of patients

\begin{tabular}{lcccccc}
\hline Age of patient $(\mathbf{y})$ & $\begin{array}{l}\text { No in age group } \\
\text { (\% of total) }\end{array}$ & Sex (M:F) & $\begin{array}{l}\text { ASA grade 1 } \\
\text { (\% of age group) }\end{array}$ & $\begin{array}{c}\text { ASA grade 2 } \\
\text { (\% of age group) }\end{array}$ & $\begin{array}{c}\text { ASA grade 3 } \\
\text { (\% of age group) }\end{array}$ & $\begin{array}{l}\text { ASA grade } 4 \\
(\% \text { of age group) }\end{array}$ \\
\hline Paediatric (aged $<16)$ & $169(1.8 \%)$ & $103: 65$ & $144(85.2 \%)$ & $15(8.9 \%)$ & $1(0.6 \%)$ & $1(0.6 \%)$ \\
Adult & $7513(81.5 \%)$ & $3773: 3700$ & $5835(77.7 \%)$ & $1188(15.8 \%)$ & $157(2.1 \%)$ & $24(0.3 \%)$ \\
Elderly care (aged $>75)$ & $1297(14.1 \%)$ & $618: 669$ & $518(39.9 \%)$ & $580(44.7 \%)$ & $118(9.1 \%)$ & $12(0.9 \%)$ \\
Unknown age & $244(2.6 \%)$ & $120: 115$ & $176(72.1 \%)$ & $44(18.0 \%)$ & $3(1.2 \%)$ & 0 \\
Total & $9223(100 \%)$ & $4614: 4549^{*}$ & $6673(72.4 \%) \dagger$ & $1827(19.8 \%)$ & $279(3.0 \%)$ & $37(0.4 \%)$ \\
\hline
\end{tabular}

*Sex not recorded in 60/9223 $(0.7 \%)$ patients.

†American Society of Anesthesiology (ASA) grade unknown in 407 (4.4\%) patients.

the terminal ileum (19.7\%), finger indentation of the right iliac fossa $(44.7 \%)$, and fluoroscopy $(0.6 \%)$.

In $2.3 \%$ of procedures, no indication was given as to the extent of the examination. One or more identifying landmarks of caecal intubation were reported in $76.9 \%$ of procedures. The intubation rate for DGHs was $4326 / 5805$ $(74.5 \%)$, teaching hospitals $1632 / 2130 \quad(76.6 \%)$, private hospitals 1046/1166 (89.7\%), and paediatric hospitals $90 / 122(73.8 \%)$. Only $13 / 68(19.1 \%)$ units achieved a $90 \%$ intubation rate (one DGH, three teaching, six private and three paediatric).

Intubation of the terminal ileum or visualisation of the ileocaecal valve are the only reliable landmarks of complete colonoscopy. When either or both of these two landmarks was recorded to define a complete procedure, only 5251/9223 $(56.9 \%)$ colonoscopies could be objectively confirmed as complete. Using this adjusted caecal intubation rate, only two hospitals achieved a $90 \%$ caecal intubation rate.

The caecal intubation rates for patients of ASA status 1, 2, 3 , and 4 were $5367 / 6673$ (80.4\%), 1342/1827 (73.5\%), 185/279 $(66.3 \%)$, and $24 / 37(64.9 \%)$, respectively. When three age groups were considered independently ( $<16$ years, 1775 years, and $>75$ years $)$, caecal intubation rates were $131 / 169(77.5 \%), 5867 / 7513(78.1 \%)$, and 917/1297 (70.7\%), respectively. When sex was analysed, caecal intubation for males was $3712 / 4614(80.5 \%)$ and $3341 / 4549$ (73.4\%) for females. Completion rate for single agent bowel preparation was $1180 / 1438(82.1 \%)$ for sodium phosphate (Fleet), $2473 / 3398(72.8 \%)$ for sodium picosulphate (Picolax), and $1542 / 1906(80.9 \%)$ for polyethylene glycol preparations (Klean prep). The caecal intubation rate was similar whether or not hyoscine butylbromide was given (1529/1901 (80.4\%) versus 5565/7322 (76.9\%)).

The caecal intubation rate was lower in the presence of a stricture. Caecal intubation was reported in only 6/30 (20\%) malignant strictures and 36/98 (36.7\%) benign strictures. In patients with non-stricturing tumours, the caecal intubation rate was $173 / 319(54.2 \%)$. Completion rate in the presence of polyps was $1713 / 2072(82.7 \%)$, diverticular disease $1053 / 1376$ $(76.5 \%)$, and inflammatory bowel disease $1010 / 1285$ (78.6\%). The proportion of normal examinations that were complete was $2972 / 3880(76.6 \%)$.

The caecal intubation rate for consultant gastroenterologists was $3245 / 3881(83.6 \%)$, gastroenterology trainees $1074 / 1333$ (80.6\%), coloproctologists 1498/2094 (71.5\%), surgical registrars $234 / 338(69.2 \%)$, and staff grades/associate specialists $739 / 1001(73.8 \%)$.

\section{Causes of failure to complete the procedure}

In $1913 / 9223(20.7 \%)$ procedures the endoscopist was unable to complete the colonoscopy. A planned limited examination was the sole reason for incomplete colonoscopy in only $1.1 \%$ of procedures. One or more reason were given for aborting the procedure. The most common cause was patient discomfort $(34.7 \%)$ followed by uncontrolled looping $(29.7 \%)$, poor bowel preparation $(19.6 \%)$, diverticulosis
$(9.5 \%)$, and adequate delineation of subtotal colitis $(2.0 \%)$. The caecum had been resected in 138/1913 (7.2\%) patients, and in $107 / 1913(5.6 \%)$ patients a tumour prevented proximal inspection of the colon. In 55/1913 (2.9\%) patients, reasons for failing to complete the procedure included bradycardia, nausea and vomiting, hypoxia, and hypotension.

\section{Diagnosis}

A diagnosis was not recorded in $3.7 \%$ of questionnaires. A normal colonoscopy to the point of maximum insertion was reported in $42.1 \%$ of procedures. A single diagnosis was reported in $39.4 \%$ and more than one diagnosis in $14.9 \%$. The most common diagnosis was polyps $(22.5 \%)$ followed by diverticular disease (14.9\%). Inflammatory bowel disease was recorded in $13.9 \%$ and carcinoma in $3.8 \%$.

\section{Therapeutic colonoscopy}

Polyps were reported in 2072/9923 (22.5\%) colonoscopies. Polypectomy was undertaken in 1880/2072 (90.7\%). All polyps were judged completely removed in $1440 / 1880$ $(76.6 \%)$. In 340/1880 (18.1\%) colonoscopies where polypectomy was undertaken the polypectomy was incomplete. Where polyps were identified, the caecal intubation rate was $1713 / 2072(82.7 \%)$.

\section{Status of the colonoscopists}

Consultants performed the majority of colonoscopies. Consultant gastroenterologists, physicians, and paediatricians performed $42.1 \%$ of procedures, consultant coloproctologists and general surgeons $22.7 \%$, and staff grade, associate specialists, and general practitioners $10.9 \%$. Medical trainees performed $14.5 \%$ of colonoscopies and surgical trainees $3.7 \%$.

\section{Training of colonoscopists}

It is recommended that trainees should be closely supervised for their first 100 colonoscopies. ${ }^{18}$ Of the 234 colonoscopists responding to the endoscopist questionnaire, only $17.0 \%$ had received supervised training for their first 100 colonoscopies. The percentage of initial procedures supervised for consultant gastroenterologists, physicians, and paediatricians was $19.6 \%$, consultant coloproctologists and general surgeons $12.2 \%$, staff grade, associate specialists, and general practitioners $33.3 \%$, medical trainees $16.7 \%$, and surgical trainees $0 \%$.

Only $39.3 \%$ of colonoscopists had ever attended a formal colonoscopy training course. Courses had been attended by $51.9 \%$ of consultant gastroenterologists, physicians, and paediatricians, $37.1 \%$ of consultant coloproctologists and general surgeons, $66.7 \%$ of staff grade, associate specialists, and general practitioners, $21.7 \%$ of medical trainees, and $15.8 \%$ of surgical trainees.

\section{Complications}

Readmission within 30 days

Of the 9223 patients, $114(1.2 \%)$ patients were admitted to hospital within 30 days of their colonoscopy. The most 
common reasons for admission were abdominal pain $(23.7 \%)$, malignancy $(8.8 \%)$, angina or myocardial infarction $(7.0 \%)$, general deterioration $(7.0 \%)$, observation $(5.3 \%)$, cerebrovascular accident $(3.5 \%)$, and pneumonia $(2.6 \%)$. Of these 114 patients, $39(34.2 \%)$ were admitted for elective surgery, both related and unrelated to colonoscopy.

\section{Bleeding following colonoscopy}

Bleeding after colonoscopy was reported in 13 patients. Six patients were admitted with rectal bleeding. One patient with bleeding had diverticular disease at colonoscopy and went on to have angiography but no bleeding point was identified. One patient who had undergone gastroscopy and a normal colonoscopy for iron deficiency was readmitted with melaena, indicating upper rather than lower gastrointestinal bleeding. The other four patients had undergone snare polypectomy, ${ }^{2}$ cold biopsy, ${ }^{1}$ and cold biopsy with snare. ${ }^{1}$ In all of these patients, the bleeding stopped without intervention or need for transfusion.

There were a further seven reports of bleeding. Five of these had either cold biopsy ${ }^{2}$ or polypectomy, ${ }^{3}$ and in three of these patients rectal bleeding was the original indication for colonoscopy. One patient on warfarin had a polyp identified at colonoscopy but there was no record of intervention and a further patient underwent colonoscopy for rectal bleeding and the patient again reported bleeding after the colonoscopy although no pathology had been identified.

A further 21 patients had bleeding requiring active intervention at the time of colonoscopy. This followed snare polypectomy, ${ }^{11}$ hot biopsy, ${ }^{5}$ cold biopsy, ${ }^{2}$ hot biopsy and snare without cautery, ${ }^{1}$ and hot biopsy and snare with cautery. ${ }^{2}$ Interventions to stop bleeding included diathermy, adrenaline injection, and stalk snaring.

\section{Perforation during colonoscopy}

Perforation was reported in 12 patients (seven males and five females, age range 30-93 years). The overall perforation rate was 1:769. In six patients the perforation was recognised at the time of colonoscopy. In two patients the complication was recognised prior to anticipated discharge and the remainder presented 1, 7, 16, and 24 days after the procedure. The site of perforation was recorded in four of the 12 patients (two rectal and two sigmoid). Only four of the perforations followed intervention. Two were associated with snare polypectomy, one with hot biopsy, and one with hot biopsy and snare polypectomy. A hot biopsy or other therapeutic procedure was undertaken in $20.0 \%$ of colonoscopies and in these, the perforation rate was 4/1841 (1:460). No cold biopsy was complicated by perforation. In $80.0 \%$ of colonoscopies, no intervention or only cold biopsies were performed. In this "non-interventional group" the perforation rate was $8 / 7382(1: 923)$.

\section{Deaths following colonoscopy}

Ten deaths were reported within 30 days of the procedure (age range $53-88$ years). In five of these patients the colonoscopy was normal. A polyp or tumour was present in three patients and melanosis coli and angiodysplasia were diagnosed in two patients. Colonoscopy was considered a possible factor in six patients while carcinomatosis was thought to have been the cause of death in three patients. One patient died in the 30 day period following repair of an aortojejunal fistula.

In those patients where the colonoscopy might have been a factor in the patient's death, four were inpatients at the time of colonoscopy. The causes of death were stroke, bronchopneumonia, myocardial infarction, and bronchopneumonia with septicaemia, respectively. One patient died at home from left ventricular failure following a myocardial infarct and a further patient was admitted 19 days after colonoscopy and died of bronchopneumonia, cirrhosis, and cardiac failure.

\section{Patient questionnaire}

Of the 1200 questionnaires sent to patients, 599 (49.9\%) were returned for analysis. Written information explaining the procedure was received by $81.5 \%$. Written consent was obtained in the procedure room in $54.8 \%$ of procedures and $29.9 \%$ were consented immediately prior to the colonoscopy but outside the procedure room. Written consent was obtained in the outpatient department in $10 \%$ of patients and $5.3 \%$ could not remember where they had provided consent. Information on possible adverse events was recalled by $54.9 \%$ and mention of "bleeding" and "perforation" were recalled in 95/329 (28.9\%) and 96/329 (29.2\%), respectively.

\section{DISCUSSION}

The potential of colonoscopy can only be realised if the procedure is completed safely with good visualisation of the mucosa. This multicentre study is the first large scale prospective evaluation of colonoscopy practice in a cross section of teaching hospitals, DGHs, private hospitals, and paediatric units.

Over the past 15 years, there has been an increasing demand for colonoscopy in the UK. In 1987, it was recommended that 160 colonoscopies should be provided annually for a population of $100000 .^{6}$ In 1990, the BSG recommended that approximately 200 colonoscopies per annum would be required to provide a service for a population of $100000 .{ }^{19}$ In 2001, the BSG working party suggested that the average DGH should plan for an annual workload of 800-1000 lower gastrointestinal procedures per 100000 population. ${ }^{20}$ This represents a fivefold increase in expectation over 15 years.

In this study, 39 DGHs performed a mean of 149 colonoscopies over the four month period (equating to 447 per annum). The 10 teaching hospitals performed a mean of 213 procedures (equating to 639 per annum). Many hospitals participating in the study serve populations well over 100000 , indicating that there is serious under provision of colonoscopy in most hospitals.

Approximately two thirds of colonic disease is within reach of a $60 \mathrm{~cm}$ flexible sigmoidoscope and many diagnoses are within range of a rigid sigmoidoscope. In this study, only half of the patients found to have a malignant looking tumour at colonoscopy had previously undergone rigid or flexible sigmoidoscopy.

Excellent bowel preparation is a prerequisite for good quality colonoscopy. Poor bowel preparation is associated with prolonged intubation time. ${ }^{21}$ Bowel preparations usually include sodium phosphate (for example, Fleet), magnesium salts (for example, Picolax), or polyethylene glycol (for example, Klean prep). A meta-analysis of sodium phosphate and polyethylene glycol showed that sodium phosphate yielded a better preparation and was better tolerated by patients than polyethylene glycol. ${ }^{22}$ Two studies comparing magnesium salt with sodium picosulphate (Picolax) and polyethylene glycol showed sodium picosulphate to be better tolerated by patients. ${ }^{23} 24$ Sodium picosulphate also gave better bowel preparation. ${ }^{24}$ Two studies comparing sodium phosphate with sodium picosulphate showed better preparation with sodium phosphate in one study and a similar outcome from both preparations in the other. ${ }^{25}{ }^{26}$ Despite these publications, sodium phosphate was the least used preparation in our study. Sodium picosulphate was the most commonly used cleansing agent followed by polyethylene glycol. It is of interest that the caecal intubation rate was higher for sodium phosphate than for sodium picosulphate 
( $82 \%$ and $73 \%$, respectively) and that the polyethylene glycol preparation was similar to sodium phosphate.

Endoscopy guidelines recommend the routine placement of an intravenous plastic cannula prior to the procedure. ${ }^{27}$ Use of a "butterfly" needle is considered unsafe. ${ }^{28}$ Prior to colonoscopy, $87 \%$ of patients were cannulated with a plastic cannula and in $11 \%$ a "butterfly" needle was used for venous access. Continuous intravenous access was not established in $2.2 \%$ of high risk patients.

Supplemental oxygen is recommended when patients are sedated. Oxygen was administered to $72 \%$ of patients who received sedation but $11.4 \%$ of high risk patients did not receive supplemental oxygen.

Prior to colonoscopy, most patients receive a combination of intravenous sedation and analgesia. Midazolam is generally the sedative of choice for short term sedation. ${ }^{29}$ Midazolam plus pethidine is the most frequently used regimen $(57.8 \%$ of colonoscopies). The recommended dose of midazolam for sedation is usually $70 \mu \mathrm{g} / \mathrm{kg}$ (that is, $5 \mathrm{mg}$ for a $70 \mathrm{~kg}$ patient) and diazepam $10-20 \mathrm{mg} .{ }^{30}$ This study indicates that a significant number of patients receive more than the recommended sedative dose of benzodiazepine; $25 \%$ of patients receiving midazolam had greater than $5.0 \mathrm{mg}$ and $8 \%$ of patients receiving diazemuls had greater than $20 \mathrm{mg}$ (36\% received more than $10 \mathrm{mg}$ ).

When combined sedation and analgesia is administered, pethidine should be injected before the benzodiazepine as this allows safer titration of the sedative drug. ${ }^{31}$ In this study, $28 \%$ of patients were given the benzodiazepine prior to pethidine. Single agent sedation was used in approximately $13 \%$ of patients and unsedated colonoscopy in $4 \%$.

Despite evidence that patient administered nitrous oxide/ oxygen inhalation provides analgesia equivalent to opiates and results in less desaturation and quicker recovery times, only $1 \%$ of colonoscopists use this approach to conscious sedation..$^{32-34}$ One controlled trial has indicated that the antispasmodic hyoscine butylbromide (Buscopan) increases the speed of colonoscope insertion. ${ }^{35}$ Teaching hospitals and DGHs used hyoscine butylbromide in $17.7 \%$ and $15.7 \%$ of procedures, respectively, while its use was reported in $52.7 \%$ of procedures in private hospitals. Caecal intubation rates were similar for procedures with and without hyoscine butylbromide.

The aim of colonoscopy is to inspect the entire colon and competent colonoscopists intubate the caecum in at least $90 \%$ of patients. ${ }^{18}$ The caecum can only be positively recognised by visualising the ileocaecal valve. ${ }^{36}$ Other signs, including transillumination, identification of the tri-radiate fold, appendix orifice, and finger indentation over the right iliac fossa, may provide misleading information.

In this study, the definition of a colonoscopy did not include examinations where the express purpose was to perform a limited left sided examination. Caecal intubation was reported in $76.9 \%$ of procedures. However, when identification of the ileocaecal valve or intubation of the terminal ileum were the only criteria used for successful colonoscopy, just $56.9 \%$ of procedures could be considered complete. This indicates that completion rates are unacceptably low.

The colonoscopist judged caecal intubation and there was no independent verification. Caecal intubation based on landmarks other than visualisation of the ileocaecal valve or terminal ileal intubation almost certainly overestimate completion rates. Restricting a complete colonoscopy to only those reports that positively identified the ileocaecal valve or intubated the terminal ileum provides an objective measure of completion and the adjusted intubation rate is considerable cause for concern. The difference between the overall and adjusted caecal intubation rate may reflect subjective optimism by the endoscopist who fails to recognise the importance of ileocaecal valve identification.

There was an inverse relationship between caecal intubation rate and increasing patient morbidity and age. Older and ill patients are more likely to require two investigations for complete assessment and therefore in some units, barium enema or computed tomography pneumocolon might be considered as an alternative first line investigation for these patients.

Completion rates were markedly reduced in the presence of a benign or malignant stricture ( $37 \%$ and $20 \%$, respectively). However, in patients with a tumour but no stricture, the caecal intubation rate was only 54\%; therefore half will require a further colonoscopy to examine the proximal colon for synchronous lesions.

Previous studies have identified colonoscopy as more difficult in females. ${ }^{14} 21$ This is reflected in our study where caecal intubation rates for men and women were $81 \%$ and $73 \%$, respectively.

Using their own criteria for caecal intubation, colonoscopists reported failure to reach the caecum in $21 \%$ of cases. The commonest reasons for incomplete colonoscopy were patient discomfort (35.3\%), looping (30.3\%), and poor bowel preparation $(19.8 \%)$. There was considerable scope for addressing each of these complications. Patient discomfort and looping often reflect poor technique. Scrupulous attention to preparation should also reduce the number of failed procedures.

Eighty three per cent of colonoscopists reported that close supervision was not provided in the early learning period and $61 \%$ had never attended a formal training course. The caecal intubation rate was higher when colonoscopy was performed by consultant gastroenterologists, physicians and paediatricians $(84 \%)$, and medical trainees $(81 \%)$. Lower completion rates were recorded for consultant coloproctologists and general surgeons $(71.5 \%)$ and surgical trainees $(69.2 \%)$. The caecal intubation rate for staff grade endoscopists, associate specialists, and general practitioners was $74 \%$. The different completion rates for medical and surgical endoscopists might reflect differences in training and case mix. Medical endoscopists received more supervision and course work than surgeons, and this may account for some of the difference. There is considerable scope to formalise training with a view to accreditation, and all colonoscopists should be encouraged to develop a plan for improving practice.

Polyps and diverticulosis accounted for the most common diagnoses. An abnormality was discovered in 54\% of procedures. When inflammatory bowel disease assessment, rectal bleeding, or clarification of barium enema were prime indications for colonoscopy, pathology was discovered in more than half of the patients. When change of bowel habit or abdominal pain was the sole indication, more than $60 \%$ of colonoscopies were reported as normal.

Polyps were discovered in $22.5 \%$ of patients and polypectomy was attempted in the majority. Incomplete polypectomy was reported in one in five colonoscopies. Failure to deal effectively with polyps leaves diagnostic uncertainty and the need to repeat the procedure. The high rate of incomplete polypectomy requires further analysis but may relate to issues of skills training.

The most serious complications of colonoscopy are perforation, bleeding, and death. For comparison, summaries of previous studies reporting complications of colonoscopy are summarised in table 3. In this study, significant bleeding requiring admission to hospital occurred in six patients (1:1537), and rarely required intervention. Twelve patients experienced myocardial infarction and/or cerebrovascular accidents. Perforation was recorded in 1:769 patients. In "non interventional" colonoscopies, eight perforations were 
Table 3 Summary of previous studies of colonoscopy complications

\begin{tabular}{|c|c|c|c|c|c|}
\hline Reference & $\begin{array}{l}\text { Prospective/ } \\
\text { retrospective }\end{array}$ & No of colonoscopies & Bleeding (\%) & Perforation (\%) & Mortality (\%) \\
\hline Eckardt $^{8}$ & Prospective & 2500 & 0.24 & 0.08 & 0 \\
\hline Jentschura 9 & Prospective & $29695^{*}$ & 0.24 & 0.10 & 0.015 \\
\hline $\operatorname{Sieg}^{10}$ & Prospective & 8416 & 0.001 & 0.005 & 0.001 \\
\hline Waye $^{11}$ & Prospective & 2097 & 1.24 & 0.10 & 0 \\
\hline Wexner $^{12}$ & Prospective & 13580 & 0.07 & 0.07 & 0.007 \\
\hline Nelson ${ }^{13}$ & Prospective & 3196 & 0.22 & 0 & 0 \\
\hline Anderson $^{14}$ & Retrospective & 10486 & N/A & 0.19 & 0.019 \\
\hline Farley $^{15}$ & Retrospective & 57028 & N/A & 0.075 & 0 \\
\hline Puchner ${ }^{16}$ & Retrospective & 10000 & 0.05 & 0.09 & 0.02 \\
\hline $\operatorname{Tran}^{17}$ & Retrospective & 26162 & N/A & 0.08 & 0.004 \\
\hline Current study & Prospective & 9223 & 0.07 & 0.13 & 0.07 \\
\hline
\end{tabular}

$\mathrm{N} / \mathrm{A}$, the study did not address bleeding rates.

*15 159 colonoscopies, 14536 rigid sigmoidoscopies.

recorded $(0.1 \%)$ and in "interventional" colonoscopies, four perforations were recorded $(0.2 \%)$.

Of the 10 deaths occurring within 30 days of the procedure, four were considered to be due to severe comorbid disease rather than the procedure itself. It is likely that these patients were extremely ill at the time of colonoscopy. The procedure related mortality was 1:1537. Overall, the bleeding and perforation rates were within the expected range but the mortality rate was higher than previously quoted. ${ }^{37}$ The increased mortality rate might be attributed to the design of the study as no other study has specified a 30 day follow up period.

The patient questionnaire indicates that most had received some form of written instruction and/or explanation prior to the procedure but the majority of patients were unaware of the major risks associated with colonoscopy. Despite recommendations that consent is sought before the patient arrives for the procedure, most patients are asked to provide consent immediately prior to the procedure and often in the endoscopy room. ${ }^{38}$ It should be possible for the consent procedure to be reassessed and changed in those units not compliant with best practice.

In summary, this cross sectional study of colonoscopic practice indicates that there is currently under provision of colonoscopy in the NHS. Screening of high risk individuals is already recommended in the UK and it has been estimated that this will require 1.25 colonoscopy sessions per week for a DGH (assuming six colonoscopies per session and a population of 250000$).{ }^{39}{ }^{40}$ It has been estimated that introduction of a faecal occult blood screening programme would require at least one extra colonoscopy session per week in a DGH. ${ }^{40}$ Unless there is a dramatic increase in manpower and resources available for lower gastrointestinal investigations, the introduction of a national screening programme would rapidly overburden already inadequate facilities.

A national agenda is necessary to address the shortfalls in current colonoscopic practice. The unacceptably low caecal intubation rate and inadequate polyp removal rate can be improved with better training. Accessible and ongoing training should be made available to both trainees and more experienced endoscopists. Teaching colonoscopy requires considerable skill and the recent establishment of "training the trainers" courses is a critical innovation which should ultimately improve performance.

In conclusion, this study of colonoscopic practice indicates that while there are centres where practice is of the highest quality, considerable effort is required to raise the overall quality of colonoscopy. High calibre early training, regular refresher courses, peer review, and continuous audit of standards at local and national levels must emerge from this study as a priority for all endoscopists performing colonoscopy.

\section{ACKNOWLEDGEMENTS}

We are very grateful to all the endoscopy units, clinicians, endoscopy staff, and audit personnel who participated in the study and without whose help the project would not have been feasible.

We thank SmithKline Beecham Pharmaceuticals for their financial support in setting up the project and Chris Romaya of the BSG Administration office.

The project was supported by the British Society of Gastroenterology, the Royal College of Physicians of London, the Royal College of Surgeons of England, the Royal College of Radiologists, the Association of Surgeons of Great Britain and Ireland, and the Association of Coloproctology of Great Britain and Ireland.

\section{Authors' affiliations}

C J A Bowles, O Epstein, Department of Gastroenterology, Royal Free Hospital, London

R Leicester, St George's Hospital, London, UK

C Romaya, BSG Administration Office, London, UK

E Swarbrick, New Cross Hospital, Wolverhampton, UK

C B Williams, St Mark's Hospital, Harrow, Middlesex, UKDepartment of Gastroenterology, Royal Free Hospital, London, UK

\section{REFERENCES}

1 Overholt BF, Pollard HM. Cancer of the colon and rectum. Current procedures for detection and diagnosis. Cancer 1967;20:445-50.

2 Office for National Statistics. Cancer statistics-registrations England, 1999. London: The Stationery Office, 2002; series MB1 No 30.

3 Hardcastle JD, Chamberlain JO, Robinson MH, et al. Randomised controlled trial of faecal-occult-blood screening for colorectal cancer. Lancet 1996;348:1472-7.

4 Kronborg O, Fenger C, Olsen J, et al. Randomised study of screening for colorectal cancer with faecal-occult-blood test. Lancet 1996;348:1467-71.

5 Mandel JS, Bond JH, Church TR, et al. Reducing mortality from colorectal cancer by screening for fecal occult blood. Minnesota Colon Cancer Control Study (erratum appears in N Engl J Med 1993;329:672). N Engl J Med 1993;328:1365-71.

6 Future requirements for colonoscopy in Britain. Report by the Endoscopy Section Committee of the British Society of Gastroenterology. Gut 1987;28:772-5.

7 Macfarlane B, Leicester R, Romaya C, et al. Colonoscopy services in the United Kingdom. Endoscopy 1999;31:409-11.

8 Eckardt VF, Kanzler G, Schmitt T, et al. Complications and adverse effects of colonoscopy with selective sedation. Gastrointest Endosc 1999;49:560-5.

9 Jentschura D, Raute M, Winter J, et al. Complications in endoscopy of the lower gastrointestinal tract. Therapy and prognosis. Surg Endos 1994;8:672-6.

10 Sieg A, Hachmoeller-Eisenbach U, Eisenbach T. Prospective evaluation of complications in outpatient $\mathrm{Gl}$ endoscopy: a survey among German gastroenterologists. Gastrointest Endos 2001;53:620-7.

11 Waye JD, Lewis BS, Yessayan S. Colonoscopy: a prospective report of complications. J Clin Gastroenterol 1992;15:347-51.

12 Wexner SD, Garbus JE, Singh JJ, et al. A prospective analysis of 13,580 colonoscopies. Reevaluation of credentialing guidelines. Surg Endos $2001 ; 15: 251-61$.

13 Nelson DB, McQauid KR, Bond JH, et al. Procedural success and complications of large-scale screening colonoscopy. Gastrointest Endos 2002;55:307-14.

14 Anderson ML, Pasha TM, Leighton JA. Endoscopic perforation of the colon: lessons from a 10-year study. Am J Gastroenterol 2000;95:3418-22.

15 Farley DR, Bannon MP, Zietlow SP, et al. Management of colonoscopic perforations. Mayo Clin Proc 1997;72:729-33. 
16 Puchner R, Allinger S, Doblhofer F, et al. Complications of diagnostic and interventional colonoscopy (German). Wiener Klinische Wochenschrift 1996; 108:142-6.

17 Tran DQ, Rosen L, Kim R, et al. Actual colonoscopy: what are the risks of perforation? Am Surg 2001;67:845-7.

18 Recommendations for training in gastrointestinal endoscopy 1999. Joint Advisory Group on Gastrointestinal Endoscopy. London: JCHMT, 1999.

19 Provision of gastrointestinal endoscopy and related services for a district general hospital. Working Party of the Clinical Services Committee of the British Society of Gastroenterology. Gut 1991;32:95-105.

20 Provision of endoscopy related services in district general hospitals. Working Party of the British Society of Gastroenterology Endoscopy Committee. London: British Society of Gastroenterology Endoscopy Committee, working party report, 2001.

21 Kim WH, Cho YJ, Park JY, et al. Factors affecting insertion time and patient discomfort during colonoscopy. Gastrointest Endosc 2000;52:600-5.

22 Hsu CW, Imperiale TF. Meta-analysis and cost comparison of polyethylene glycol lavage versus sodium phosphate for colonoscopy preparation. Gastrointest Endosc 1998:48:276-82.

23 Hamilton D, Mulcahy D, Walsh D, et al. Sodium picosulphate compared with polyethylene glycol solution for large bowel lavage: a prospective randomised trial. Br J Clin Pract 1996;50:73-5.

24 Hawkins S, Bezuidenhout $P$, Shorvon $P$, et al. Barium enema preparation: a study of low-residue diet, 'Picolax' and 'Kleen-Prep'. Australas Radiol 1996;40:235-9.

25 Macleod AJ, Duncan KA, Pearson RH, et al. A comparison of Fleet Phosphosoda with Picolax in the preparation of the colon for double contrast barium enema. Clin Radiol 1998:53:612-14.

26 Yoshioka K, Connolly AB, Ogunbiyi OA, et al. Randomized trial of oral sodium phosphate compared with oral sodium picosulphate (Picolax) for elective colorectal surgery and colonoscopy. Dig Surg 2000;17:66-70.

27 Bell GD, McCloy RF, Charlton JE, et al. Recommendations for standards of sedation and patient monitoring during gastrointestinal endoscopy. Gut $1991 ; 32: 823-7$.
28 Smith MR, Bell GD, Fulton B, et al. A comparison of winged steel needles and Teflon cannulas in maintaining intravenous access during gastrointestinal endoscopy. Gastrointest Endos 1993;39:33-6.

29 Ginsberg GG, Lewis JH, Gallagher JE, et al. Diazepam versus midazolam for colonoscopy: a prospective evaluation of predicted versus actual dosing requirements. Gastrointest Endosc 1992;38:651-6.

30 British National Formulary, 43rd edn. London: British Medical Association and Royal Pharmaceutical Society of Great Britain, 2002

31 Ben Shlomo I, abd-el-Khalim H, Ezry J, et al. Midazolam acts synergistically with fentanyl for induction of anaesthesia. Br J Anaesth 1990:64:45-7.

32 Harding TA, Gibson JA. The use of inhaled nitrous oxide for flexible sigmoidoscopy: a placebo-controlled trial. Endoscopy 2000;32:457-60.

33 Notini-Gudmarsson AK, Dolk A, Jakobsson J, et al. Nitrous oxide: a valuable alternative for pain relief and sedation during routine colonoscopy. Endoscopy 1996;28:283-7.

34 Saunders BP, Fukumoto M, Halligan S, et al. Patient-administered nitrous oxide/oxygen inhalation provides effective sedation and analgesia for colonoscopy. Gastrointest Endosc 1994;40:418-21.

35 Saunders BP, Williams CB. Premedication with intravenous antispasmodic speeds colonoscope insertion. Gastrointest Endosc 1996;43:209-1 1.

36 Cirocco WC, Rusin LC. Confirmation of cecal intubation during colonoscopy. Dis Colon Rectum 1995;38:402-6.

37 Winawer SJ, Fletcher RH, Miller L, et al. Colorectal cancer screening: clinical guidelines and rationale (erratum appears in Gastroenterology 1997; 112:1060; Gastroenterology 1998;114:625]). Gastroenterology $1997 ; 112: 594-642$.

38 Seeking patients' consent: the ethical considerations. London: General Medical Council, 2002.

39 Cairns S, Scholefield JH. Guidelines for colorectal cancer screening in high risk groups. Gut 2002;51:1v-2.

40 Rhodes JM. Colorectal cancer screening in the UK: Joint Position Statement by the British Society of Gastroenterology, the Royal College of Physicians, and the Association of Coloproctology of Great Britain and Ireland. Gut 2000;46:746-8.

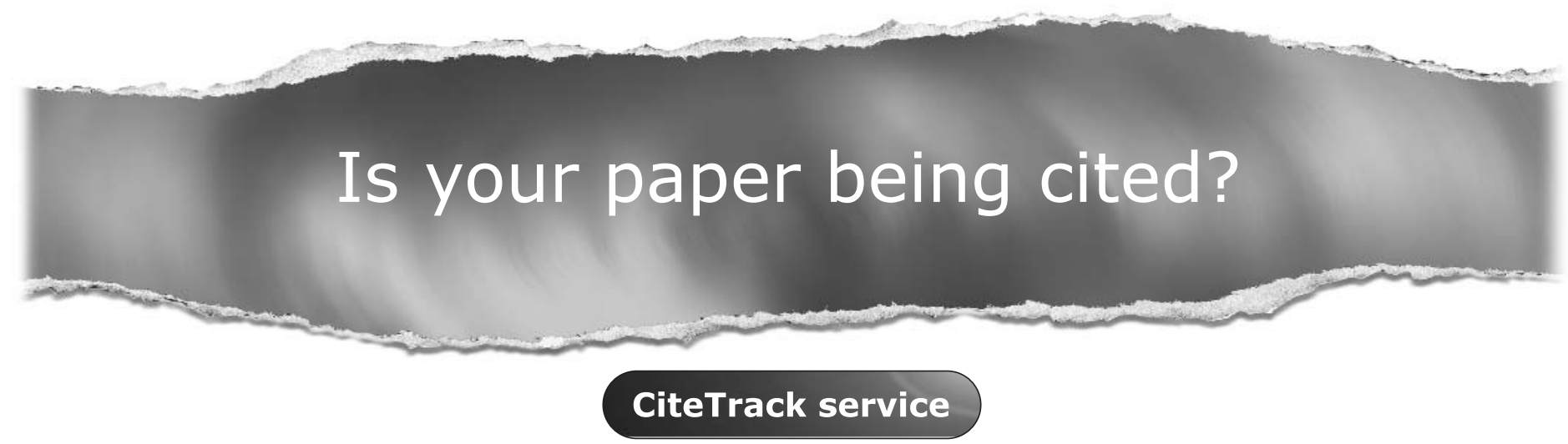

CiteTrack will alert you by email whenever new content in Gut or a participating journal is published that matches criteria you want to track

Topics: Tell CiteTrack which words or subjects to watch for in new content Authors: Be alerted whenever key authors you are following publish a new paper Articles: Know whenever a paper of interest to you is referenced by another paper

\section{www.gutjnl.com}

